\title{
Pengaruh Diameter Lubang Pada Faktor Konsentrasi Tegangan Untuk Plat Isotropis
}

\author{
Rakhmad Arief Siregar ${ }^{*}$, Khairul Umurani, Rahmatullah dan S.A. Cahyo \\ Fakultas Teknik Universitas Muhammadiyah Sumatera Utara \\ Jalan Kapten Muchtar Basri No.3 Medan 20238, Indonesia \\ *Email: rakhmadarief@umsu.ac.id
}

\begin{abstract}
ABSTRAK
Pengaruh diameter lubang terhadap tegangan pada plat isotropis dikaji secara eksperimen dan numerik menggunakan analisa elemen hingga. Kajian ini digunakan untuk menganalisis faktor konsentrasi tegangan (FKT) pada plat. Pada pengujian eksperimen plat lubang tunggal berbahan tembaga diuji tarik dengan menggunakan mesin tes universal sedangkan pada kajian numerik plat dengan lubang ganda ditarik dengan tegangan yang sama pada semua sisi. Tegangan von misses digunakan untuk menentukan FKT pada diameter dan jarak lubang yang bervariasi.. Pengaruh diameter lubang dalam bentuk kurva FKT menunjukan hasil yang bersesuaian antara eksperimen, analisa elemen hingga dan analitis.
\end{abstract}

Kata kunci : Lubang bundar, Faktor Konsentrasi Tegangan, Analisa Elemen Hingga

\section{Effect of Hole Diameters on Stress Concentration Factor for Isotropic Plate}

\begin{abstract}
The effect of hole diameter on stress for plates was studied experimentally and Numericallay using finite element analysis. This study is used to analyze the stress concentration factor (SCF) on the plate. In the experimental test a single hole plate made of copper was tested by using a universal test machine while in numerical studies a plate with a double hole is loaded with tensile stress on all sides. The von misses stress is used to determine the SCF in the varying diameter and length of the hole. The influence of hole diameter in the form of the SCF curve show results that correspond between experiments, finite element analysis and analytical analysis.
\end{abstract}

Keywords : Circular hole, Stress Concentration Factor, Finite Elemen Analysis

\section{PENDAHULUAN}

Retakan pada plat seringkali bermula dan merambat dari titik dimana konsentrasi tegangan berada. Konsentrasi tegangan terjadi pada bentuk geometri seperti bahu, alur, lubang, dan ulir. Bentukbentuk tersebut sangat sulit untuk dihindari dalam perancangan sebuah produk. Salah satu bentuk yaitu yang menjadi banyak perhatian adalah bentuk lubang yang biasanya digunakan sebagai tempat baut dalam sambungan. Perancang mesin harus mengamati konsentrasi tegangan pada lubang dengan merujuk pada hasil-hasil penelitian [1]. David D, menambah kajian secara analitis tentang dua konsentrasi tegangan dalam kondisi anisotropis. Hubungan konstitutif didasarkan pada teori aliran anisotropik bersama dengan karakteristik pengerasan linier. Penelitian ini menunjukkan bahwa kondisi anisotropis plastis juga mempengaruhi konsentrasi tegangan pada lubang [2]. Selanjutnya kajian tentang konsentrasi pada lubang banyak mengarah kepada penggunaan 


\section{Published Maret 2019 \\ Jurnal Rekayasa Material, Manufaktur dan Energi http://jurnal.umsu.ac.id/index.php/RMME}

perangkat lunak elemen hingga dalam meneliti konsentrasi tegangan [3-5]. Masih menggunakan perangkat lunak elemen hingga, Evansa mengkaji bagaimana meningkatkan faktor intensitas tegangan pada sambungan yang diberi beban [6].

Dengan menggunakan metode elemen hingga versi- $p$ secara tiga-dimensidiperoleh beberapa perbedaan signifikan dengan yang ada di literatur disebabkan oleh asumsi penyederhanaan yang digunakan sebelumnya. Untuk lubang-lubang yang berdekatan, Kh. Fuad meneliti faktor konsentrasi tegangan untuk berbagai konfigurasi [7]. Dalam penelitian ini, lubang tunggal dianalisa secara eksperimental dan numerik, sedangkan lubang ganda dengan variasi jarak dikaji menggunakan software LS-DYNA. Hasil FKT untuk setiap kasus diplot sehubungan dengan rasio jarak antara lubang yang berdekatan dengan diameter lubang.

\section{METODE PENELITIAN}

Analisa distribusi tegangan pada lubang berdiameter dilakukan dengan mengasumsikan terjadi pada plat tipis dengan kondisi isotopis. Dua pembebanan dikenakan pada plat tipis yaitu (1) beban uniaksial dan (2) hidrostatis. Pada pembebanan uniaksial.dilakukan secara eksperimental dan dibandingkan hasilnya dengan hasil secara analitis. Pengujian dilakukan menggunakan plat tembaga dengan tebal $t=5 \mathrm{~mm}$ yang ditarik di mesin uji unviersal. Untuk mendapatkan perbandingan $d / w$ (diameter per lebar) yang bersesuaian plat dilubangi dengan diameter mulai dari $3 \mathrm{~mm}$ sampai $21 \mathrm{~mm}$. Dimensi spesimen secara lengkap diperlihatkan dalam Table 1. Untuk menghitung FKT, dalam pengujian digunakan pendekatan bahwa tegangan yang terjadi disekitar adalah 3 kali dari tegangan yang terjadi pada plat seperti dalam Pers. 1.

Untuk mengamati FKT pada lubang ganda, digunakan pembebanan hidrostatis yang dilakukan pada perangkat lunak elemen hingga, LS-DYNA. Dengan menggunakan plat dengan tebal yang bervariasi jarak lubang diatur sedemikian rupa agar diperoleh perbandingan $L / d$ (jarak lubang per diameter lubang) yang bersesuaian. Tegangan maksimumm von misses yang terjadi pada daerah sekitar lubang digunakan dalam perhitungan TKT seperti dalam Pers. 2.

$$
\begin{gathered}
K_{t}=\frac{\sigma_{\text {max }}}{\sigma_{\text {nom }}}=\frac{\sigma_{\text {sekitar lubang }}}{\sigma_{\text {tanpa lubang }}} \\
K_{t}=\frac{\sigma_{\text {max von mises sekitar lubang }}}{\sigma_{\text {von mises tanpa lubang }}}
\end{gathered}
$$

Tabel 1. Ukuran spesimen plat.

\begin{tabular}{cccc}
\hline $\begin{array}{c}\text { Diameter }(d) \\
\mathrm{mm}\end{array}$ & $\begin{array}{c}\text { Lebar }(w) \\
\mathrm{mm}\end{array}$ & $\begin{array}{c}\text { Tebal }(t) \\
\mathrm{mm}\end{array}$ & $d / w$ \\
\hline 0 & & & - \\
3 & & & 0,1 \\
6 & & & 0,2 \\
9 & 30 & 5 & 0,3 \\
12 & & & 0,4 \\
15 & & & 0,5 \\
18 & & & 0,6 \\
21 & & & 0,7 \\
\hline
\end{tabular}

Copyright ${ }^{\odot} 2019$ Jurnal Rekayasa Material, Manufaktur dan Energi. This is an open acces article under the CC-BY-SA lisence (https://creativecommons.org/licenses/by-sa/4.0/). 


\section{Published Maret 2019 \\ Jurnal Rekayasa Material, Manufaktur dan Energi http://jurnal.umsu.ac.id/index.php/RMME}

\section{HASIL DAN PEMBAHASAN}

Gambar spesimen tembaga hasil pengujian tarik diperlihatkan dalam Gambar 1. Secara keseluruhan ada 8 spesimen yang sukses diuji dengan posisi patah berada disekitar tengah spesimen dengan bentuk lurus kecuali untuk spesimen dengan diameter $3 \mathrm{~mm}$. Dengan menggunakan luas permukaan yang tetap yaitu $150 \mathrm{~mm}^{2}$ maka perhitungan tegangan maksimum yang terjadi dapat dilihat pada Tabel 2. Untuk menghitung FKT digunakan Pers. 1 dengan pengandaian tegangan pada sekitar lubang 3 kali dari tegangan maksimum [1]. Hasil FKT diperiksa dengan membandingkannya dengan hasil analitik yang dibahas oleh Walter dengan penggunakan persamaan berikut.

$$
\begin{gathered}
K_{t n}=2+\left(1-\frac{d}{H}\right)^{3} \\
K_{t g}=\frac{2+(1-d / H)^{3}}{1-(d / H)}
\end{gathered}
$$

Hasil FKT yang membandingkan dengan $K_{t n}$ dan $K_{t g}$ diperlihatkan dalam Gambar 1 . Gamabr 1 (b) memperlihatkan bahwa hasil pengujian secara eksperimen memiliki korelasi yang baik dengan hasil analitis. Untuk lubang ganda, hasil analisa FKT diperlihatkan pada Gambar 3. Dengan menggunakan mesh seperti dalam Gambar 4(a), konsentrasi tegangan akan terbentuk disekitar lubang-lubang 4(b). Tegangan maksimum von misses diamateri di sekitar lubang dan digunakan untuk menghitung TFT seperti dalam Pers. 2. Diperoleh hasil bahwa FKT pada lubang ganda lebih rendah daripada yang terjadi lubang tunggal.

Tabel 2. Faktor konsentrasi tegangan.

\begin{tabular}{ccccc}
\hline & Beban Maks. $(F)$ & $\begin{array}{c}\text { Tegangan } \\
\text { Maks }(\sigma) \\
\mathrm{MPa}\end{array}$ & $\begin{array}{c}\text { Tegangan Maks. } \\
\text { sekitar Lubang } \\
\left(\sigma_{\theta A}=3 \sigma\right) \mathrm{MPa}\end{array}$ & $\begin{array}{c}\text { FKT } \\
K_{t}\end{array}$ \\
\hline 0,1 & 207.53 & 13.6 & 40.8 & 2.68 \\
0,2 & 187.55 & 12.3 & 36.9 & 2.43 \\
0,3 & 170.38 & 11.1 & 33.3 & 2.19 \\
0,4 & 157.11 & 10.3 & 30.9 & 2.03 \\
0,5 & 154.76 & 10.1 & 30.3 & 1.99 \\
0,6 & 146.83 & 9.6 & 28.8 & 1.89 \\
0,7 & 137.53 & 9.0 & 27 & 1.78 \\
\hline
\end{tabular}


Jurnal Rekayasa Material, Manufaktur dan Energi, Vol. 2, No. 1, Maret 2019, 17-23

DOI:https://doi.org/10.30596/rmme.v2i1.3065

\section{Published Maret 2019 \\ Jurnal Rekayasa Material, Manufaktur dan Energi http://jurnal.umsu.ac.id/index.php/RMME}
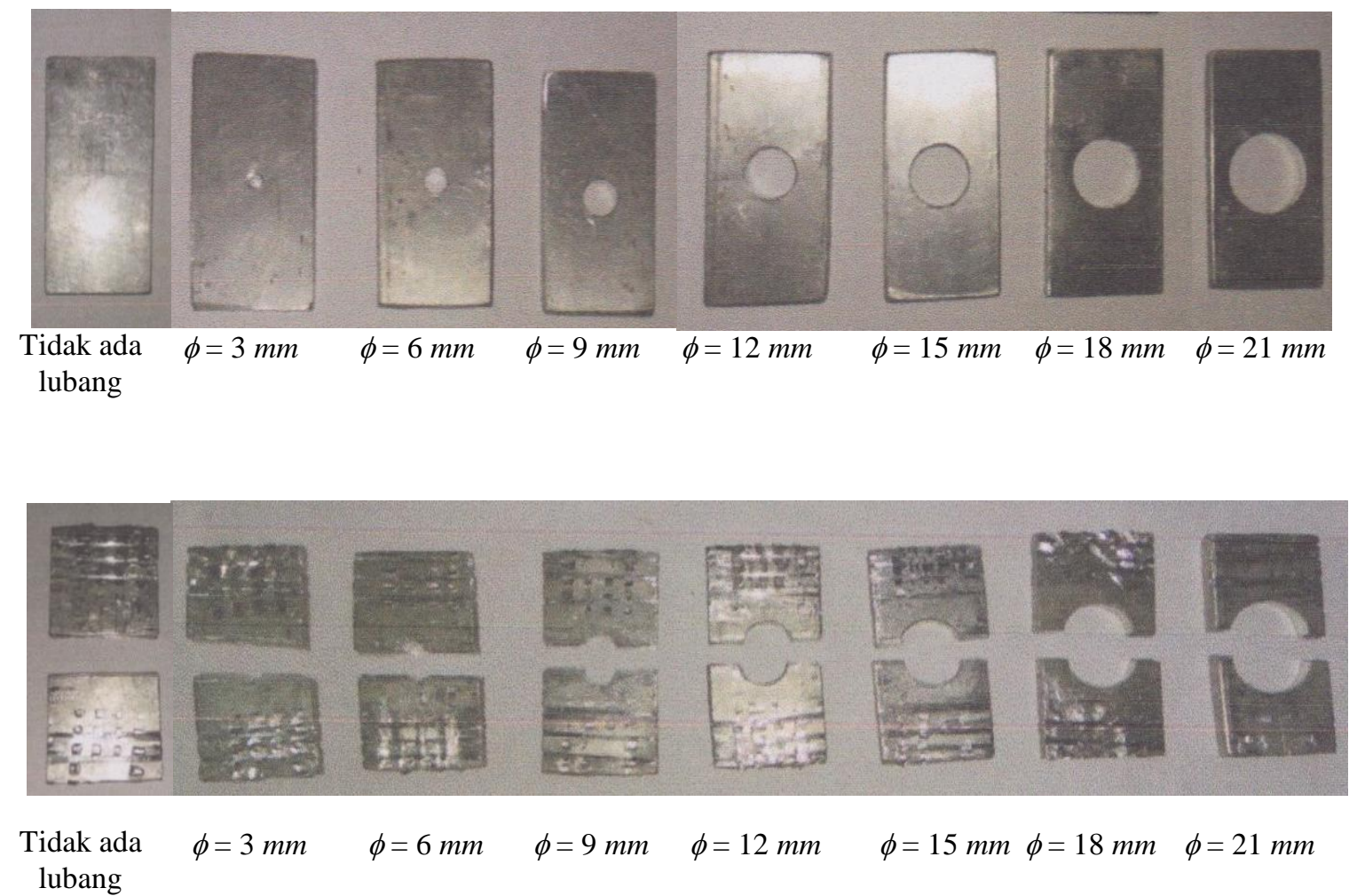

Gambar 1. Spesimen dengan variasi diameter lubang (a) sebelum pengujian, (b) setelah pengujian. 


\section{Published Maret 2019 \\ Jurnal Rekayasa Material, Manufaktur dan Energi http://jurnal.umsu.ac.id/index.php/RMME}
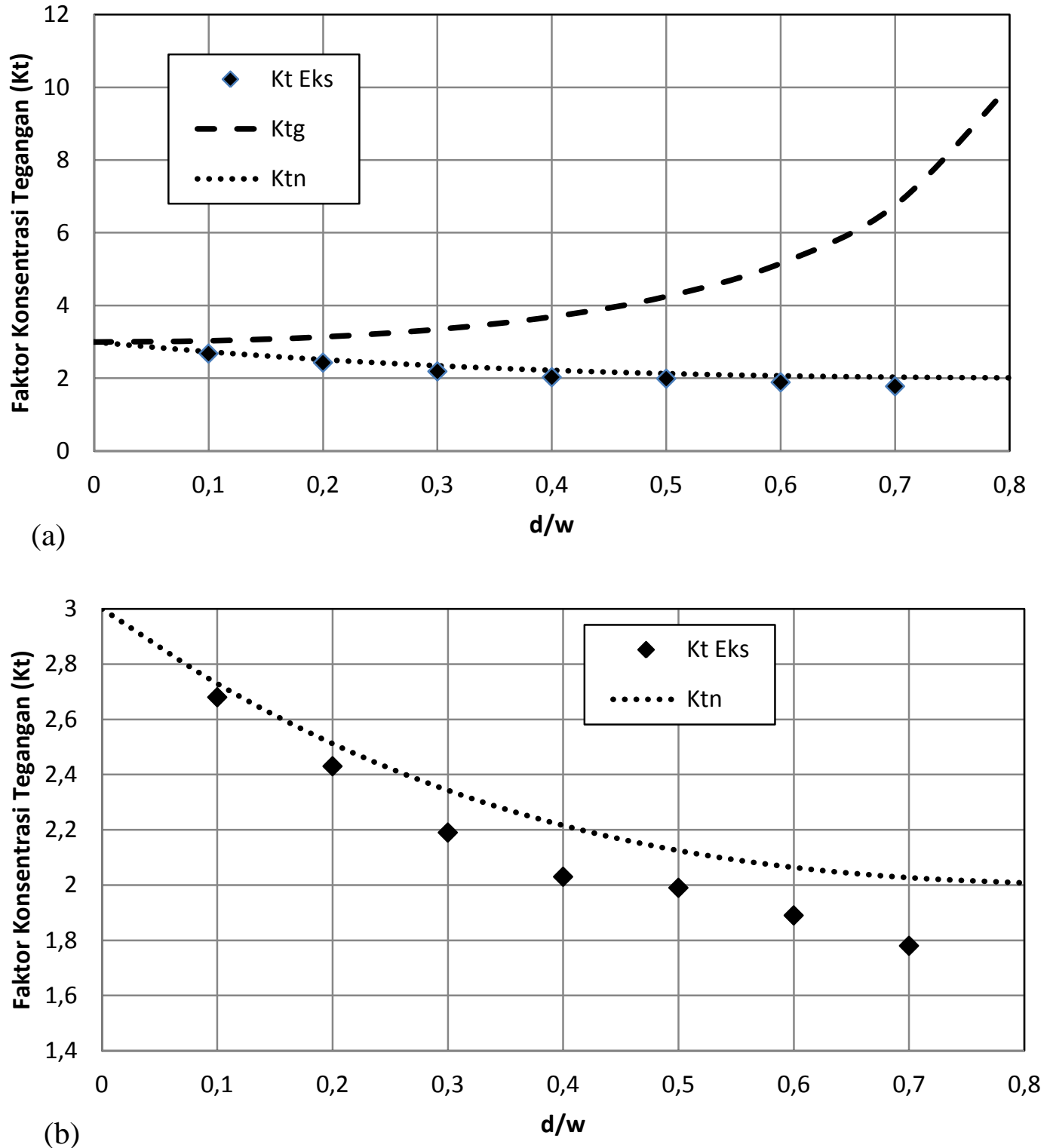

Gambar 2. Hasil perbandingan FKT secara ekperimen dengan formula Heywood[1]. 


\section{Published Maret 2019 \\ Jurnal Rekayasa Material, Manufaktur dan Energi http://jurnal.umsu.ac.id/index.php/RMME}

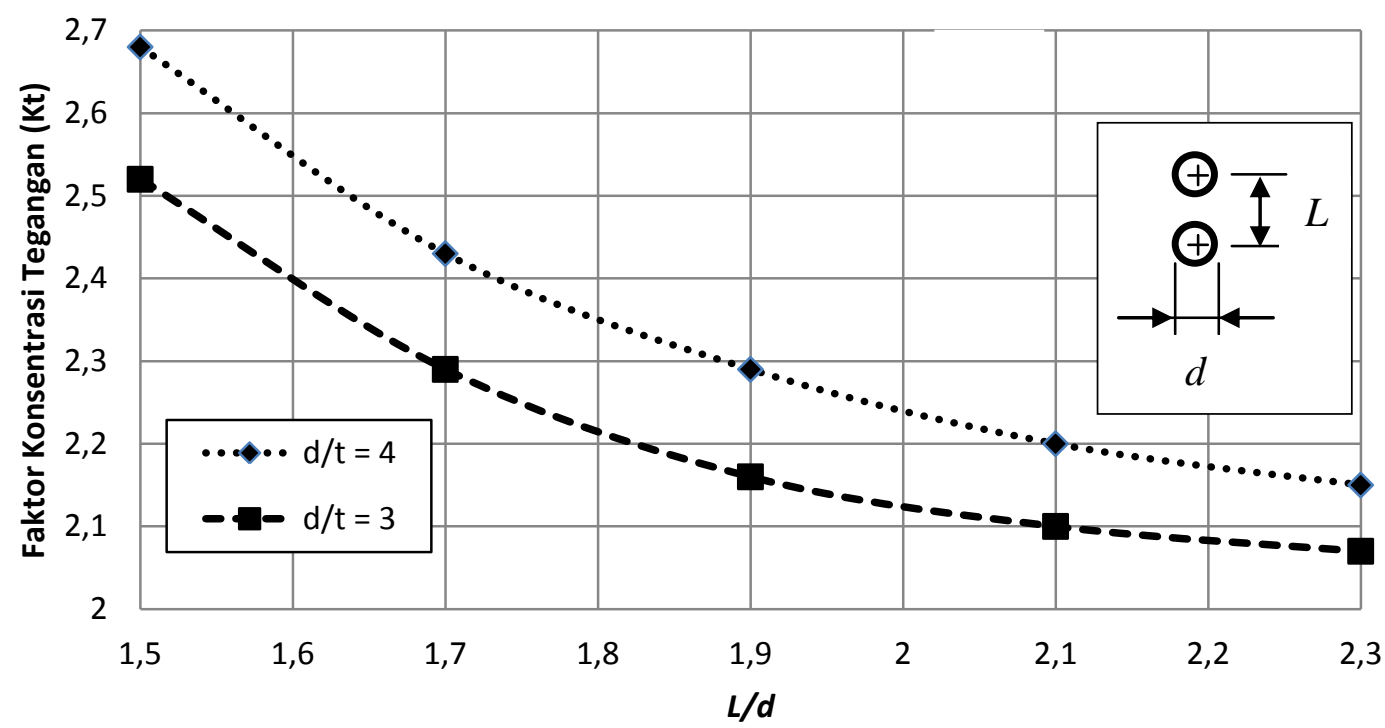

Gambar 3. Faktor konsentrasi tegangan untuk lubang ganda.

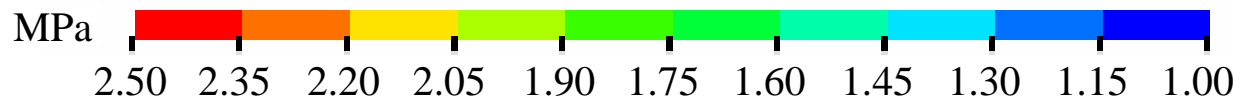

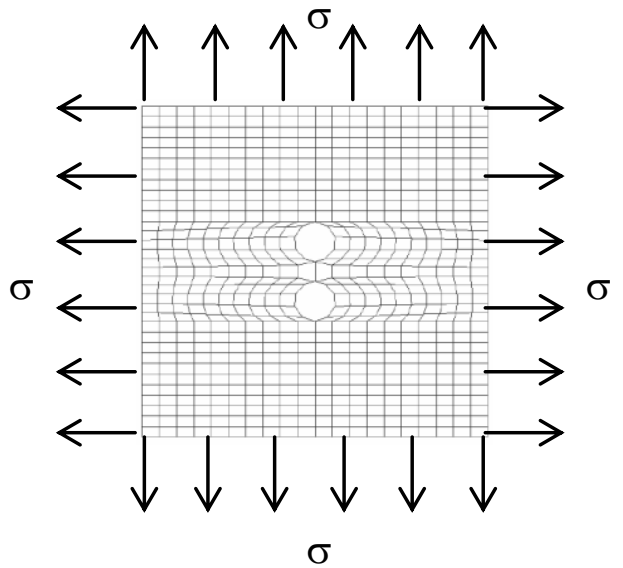

(a)

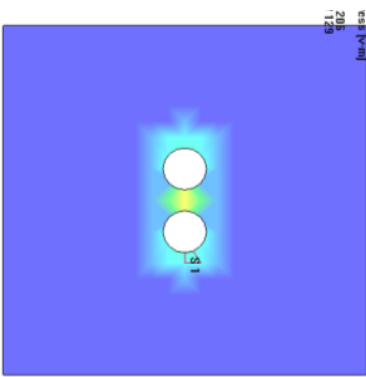

(b)

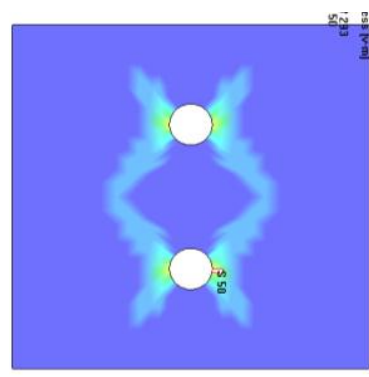

(c)

Gambar 4. Mesh elemen hingga untuk lubang tunggal dan ganda. 


\title{
Published Maret 2019 \\ Jurnal Rekayasa Material, Manufaktur dan Energi http://jurnal.umsu.ac.id/index.php/RMME
}

\begin{abstract}
KESIMPULAN
FKT untuk lubang tunggal dan ganda telah dibahas secara eksperimen dan menggunakan analisis elemen hingga. Untuk lubang tunggal hasil eksperimen menunjukan pola penurunan yang sama dengan hasil analitik. Untuk lubang ganda ditemukan penurunan perbandingan $L / d$ yang dipengaruhi peningkatan FKT secara signifikan. Sebagai perbandingan lubang ganda efektif untuk mengurangi konsentrasi tegangan daripada lubang tunggal.
\end{abstract}

\section{DAFTAR PUSTAKA}

[1] Walter D.Pilkey, Peterson's stress concentration factors, 2ndEd., John Wiley \& Sons, Inc., 1997, pp.176-260..

[2] David Durban, On Two Stress Concentration Problems In Plane-Stress Anisotropic Plasticity, Int J. Solids Structural, Vol. 23, No. 4, 1987, pp. 469-484.

[3] Lican Zhuang, Bixin Su, Minghao Lin, Yiyuan Liao, Yafang Peng, Yinglong Zhou, Dongmei Luo, "Influence of the property of hole on stress concentration factor for isotropic plates", 10th International Conference on Composite Science and Technology, Durban, South Africa, 1996, pp.1-5.

[4] Hwai-Chung $\mathrm{Wu}$, Bin $\mathrm{Mu}$, On stress concentrations for isotropic/orthotropic plates and cylinders with a circular hole, Compos. B Eng., 2003, 34, pp. 127-134.

[5] Zheng Yang, Chang-Boo Kim, Chongdu Cho, Hyeon Gyu Beom, The concentration of stress and strain in finite thickness elastic plate containing a circular hole, Int. J.Solids and Structures, 45, 2008, pp. 713-731.

[6] R. Evansa, A Clarkeb, M. Hellera, R. Stewartb, Improved stress intensity factors for a single corner crack at a loaded fastener hole, Engineering Fracture Mechanics, 2014.

[7] Kh. Fuad, R.A. Siregar, Ch. Rangkuti, B. Ariwahjoedi,M. Firdaus, Stress Concentration Factors of Various Adjacent Holes Configurations in a Spherical Pressure Vessel, $8^{\text {th }}$ Australasian Congress on Applied Mecanics, ACAM 2007.

[8] Dwi Basuki Wibowo, Sugiyanto, Agus Suprihanto, Perhitungan Faktor Konsentrasi Tegangan Pada Pipa Konstruksi Percabangan $60^{\circ}$ Akibat Gaya Aksial Menggunakan Metode Elemen Hingga, Traksi, Vol 5, No 1, 2007. 